\title{
Improved activity of $\beta$-cyclodextrin glycosyltransferase from Bacillus sp. $N-227$ via mutagenesis of the conserved residues
}

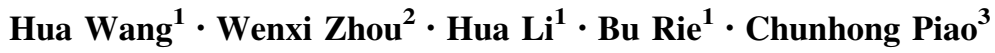

Received: 14 September 2016/Accepted: 6 April 2017/Published online: 8 June 2017

(C) Springer-Verlag Berlin Heidelberg 2017

\begin{abstract}
Cyclodextrin glycosyltransferase ( $\beta$-CGTase) belongs to the $\alpha$-amylase family of enzymes and converts starch to cyclic oligosaccharides called $\beta$-cyclodextrins ( $\beta$ CD). The $\beta$-CGTase from alkalophilic Bacillus sp. $N$-227 was separately mutagenized to give three site-directed $\beta$ CGTase mutants, Y127F, R254F and D355R, that showed enhanced cyclization activity towards a starch substrate from 1.64 to 2.1 -folds. Kinetic studies indicate that the mutants had higher affinity towards the substrate than the wild type $\beta$-CGTase. The Y127F mutant had the highest affinity which was indicated by the lowest $K_{\mathrm{m}}$ of $15.30 \mathrm{mM}$ and the highest catalytic activity. Increasing hydrophobicity around the catalytic center appeared to favor the cyclization activity of the mutants. The $\beta$ CGTase and the three mutants showed optimal enzyme activity at $60{ }^{\circ} \mathrm{C}$ and $\mathrm{pH}$ 6.0. All the enzymes were stable for at least $60 \mathrm{~min}$ across a wide $\mathrm{pH}$ range (5.0-7.0).
\end{abstract}

Keywords $\beta$-Cyclodextrin glycosyltransferase · Cyclization activity · Optimum $\mathrm{pH} \cdot$ Optimum temperature - Site-directed mutagenesis

Hua Wang

doccnrb@163.com

1 College of Life Science, Inner Mongolia University for Nationalities, Tongliao 028000, Inner Mongolia, China

2 Tongliao Academy of Agricultural Sciences, Tongliao 028000, Inner Mongolia, China

3 College of Food Science and Engineering, Jilin Agricultural University, Changchun 130118, China

\section{Introduction}

Cyclodextrin glycosyltransferase (EC 2.4.1.19, CGTase) belongs to the $\alpha$-amylase family of enzymes (Bautista et al. 2012; Janecek and Sevcik 1999; MacGregor et al. 2001), which catalyzes three type reactions towards starch, namely cyclization to yield cyclodextrins (CDs), hydrolysis, and disproportionation (van der Veen et al. 2000b, c). Catalysis of cyclization is the primary function of CGTase (Leemhuis et al. 2010). The well-characterized forms of CDs are $\alpha-, \beta-$ and $\gamma-\mathrm{CD}$ that consist of six, seven and eight-D glucose units, respectively (Goh et al. 2009). Among them, the $\beta$-CD harbors a hydrophobic internal cavity and a hydrophilic outer surface, which endows $\beta-C D$ with the water-soluble capacity (Szejtli 1990).

These properties make $\beta$-CD highly attractive for diverse applications in the field of industry, cavitation, food, medicine, as well as cosmetic (Astray et al. 2010; Slominska et al. 2002; Stella and He 2008; Szente and Szejtli 2004). The widespread use of $\beta$-CD suggests the importance for controlling the activity of $\beta$-CGTase. Previous studies have shown that mutations in the amino residues of $\beta$-CGTase influence the enzyme activity of $\beta$ CGTase at different levels (Leemhuis et al. 2002a, 2003b, 2004a, b; Penninga et al. 1995; van der Veen et al. 2000a). W652G amino acid substitution of $\beta$-CGTase in Bacillus firmus var. alkalophilus enhanced the cyclization activity and decreased the hydrolytic activity of $\beta$ CGTase (Hyun-Dong et al. 2000). Contrarily, mutant A230V CGTase in Bacillus circulans strain 251 improved the hydrolytic activity but reduced cyclization activity (Leemhuis et al. 2003a). Additionally, Dijkhuizen and collages uncovered that mutation of tyrosine 195, which located in the central active site cleft of CGTase, significantly suppressed the cyclodextrin formation (Penninga 
et al. 1995). The amino acid side chain at conserved Phe260 residues also regulated the hydrolytic activity of CGTase. Mutation of Phe260 converts CGTase from a transglycosylase into a starch hydrolase (Leemhuis et al. 2002a). Beyond these findings, the conserved residue Asp135 was reported to be required for the proper conformation of amino residues in the catalytic sites and activity (Leemhuis et al. 2003b). Results from the Leemhuis.H. demonstrated that substrate-binding site mutations of CGTase including Y167F, G179L, G180L, N193G and N193L exhibited decreased $\beta-C D$ production, disproportionation as well as coupling reactions (Leemhuis et al. 2002b). All these findings suggested that amino acid mutations in the conserved and critical sites regulate the activity of CGTase. Therefore, it is desirable to prepare, characterize and study other novel mutants that may improve the activity of $\beta$-CGTase.

The structure of $\beta$-CGTase consists of five domains (Klein et al. 1992). Domains A and B are responsible for the catalytic activity of CGTase, while domains $\mathrm{C}$ and $\mathrm{E}$ mediate the binding to raw starch (Lawson et al. 1994; Penninga et al. 1996). The function of domain $\mathrm{D}$ remains to be illustrated. It was reported that Arg204 plus the three catalytic residues Asp206, Glu230 as well as Asp297 are totally conserved in the $\alpha$-amylase family (Janecek 2002). Additionally, seven conserved sequence regions covering strand beta 2 , beta 3 , beta 4 , beta 5 , beta 7 and beta 8 of the catalytic (beta/alpha)(8)-barrel as well as the C-terminus of domain B have been identified (Janecek 2002). These conserved regions contain the catalytic, specificity and substrate-binding residues (Janecek 2002). The crystal structure of $\beta$-CGTase from Bacillus circulans strain 251 has been resolved (Lawson et al. 1994). The $\beta$-CGTase from Bacillus sp. $\mathrm{N}-227$ in this study has identical amino acid sequence as the $\beta$-CGTase from Bacillus circulans. A Swiss Model structure based on a template (PDB ID: 1pamB) is available. The three-dimensional structure of the $\beta$-CGTase revealed a 'pocket' or substrate-binding cleft which is the activity center of the enzyme. We report here three mutants of this $\beta$-CGTase, Y127F, R254F and D355R corresponding to variant positions located in Domain $\mathrm{A}$, a part of the catalytic center, and their improved catalytic activity towards cyclization of starch.

\section{Materials and methods}

\section{Strain and culture condition}

The wild type $\beta$-CGTase from Bacillus sp. N-227 (GenBank accession DQ631916) and Escherichia coli strain BL21 (DE3) was provided by the Technology Center of Bright Dairy \& Food Co. Ltd. (Shanghai, China). The $\beta$ -
CGTase expression plasmid was based on the pET-28b vector and also generated by the Technology Center (The $\beta$-CGTase bacterial expression plasmid (pET-28b- $\beta$ CGTase-6xHis) which expresses the $\beta$-CGTase-6xHis fusion protein was purchased from the Technology Center).

\section{Culture conditions}

The seed medium components, $1 \%$ tryptone, $1 \% \mathrm{NaCl}$, and $0.5 \%$ yeast extract, were dissolved in distilled water in a total volume of $1 \mathrm{~L}$, and then sterilized by autoclaving at $118^{\circ} \mathrm{C}$ for $20 \mathrm{~min}$.

\section{Introduction of mutations by using overlap extension PCR}

Overlap extension PCR is a well-established PCR amplification method that can be used to introduce and recover mutations in specific DNA sequences without the requirement for restriction enzyme sites (Angelaccio and di Patti 2002).

\section{Primers}

Based on the homologous nucleotide sequences of the wild type $\beta$-CGTase from Bacillus sp. N-227 (GenBank accession DQ631916), four pairs of primers were designed using Primer Premier 6.0 and Oligo 6.0 software. Three of the 4 pairs of primers had the desired substitution (Table 1).

\section{Overlap extension PCR analysis}

Overlap extension PCR was performed using the ABI Step One Plus system (Applied Biosystems) followed by melting curve analysis with the cycling programs described below. For the first round of PCR, pET-28b (pET-28b- $\beta$ CGTase-6xHis) was used as the template for production of ORF-1 and ORF-2. Initial denaturation was at $94^{\circ} \mathrm{C}$ for 5 min, followed by 35 cycles of $94{ }^{\circ} \mathrm{C}$ for $45 \mathrm{~s}, 55^{\circ} \mathrm{C}$ for $45 \mathrm{~s}$ and $72{ }^{\circ} \mathrm{C}$ for $90 \mathrm{~s}$. A final extension of $72{ }^{\circ} \mathrm{C}$ for $10 \mathrm{~min}$ was performed, followed by storage of products at $4{ }^{\circ} \mathrm{C}$. A mixture of ORF-1 and ORF-2 was used as the template to produce the mutated gene fragment during the second round of PCR. The procedure involved initial denaturation at $94{ }^{\circ} \mathrm{C}$ for $5 \mathrm{~min}$, followed by 35 cycles of denaturation at $94{ }^{\circ} \mathrm{C}$ for $45 \mathrm{~s}, 55^{\circ} \mathrm{C}$ for $45 \mathrm{~s}$, and $72{ }^{\circ} \mathrm{C}$ for $10 \mathrm{~min}$. Taq polymerase was then added into the system, and the reaction was continued at $72{ }^{\circ} \mathrm{C}$ for a further $30 \mathrm{~min}$. The samples were stored at $4{ }^{\circ} \mathrm{C}$.

\section{In vitro protein synthesis}

A gel extraction kit (TIGEN Biotech) was used to isolate the PCR fragments which were then ligated into the 
Table 1 Primers used in overlap extension PCR

\begin{tabular}{lll}
\hline Primers & Primer sequence $\left(5^{\prime} \rightarrow 3^{\prime}\right)$ & \\
\hline F1 & CAAGCCATGGAAAGATTTATGAAA & $\beta$-CGTase \\
R2 & ATTAT CTCGAGCTATTA AGGCTGCC & \\
F(YF)2 & TGAGCTTATCACGGCttcTGGGCGCGGGACTCA & Y127F \\
R(YF) 1 & TGAGTCCCGCGCCCAgaaGCCGTGATAAGCTCA & \\
F(RF) 2 & TCGGGGTTGACGGCATTttcGTGGACGCGGTCAAGC & R254F \\
R(RF) 1 & GCTTGACCGCGTCCACgaaAATGCCGTCAACCCCGA & \\
F(DR)2 & CTTCATCGACAATCATcgcATGGAGCGTTTCCACAC & D355R \\
R(DR $) 1$ & GTGTGGAAACGCTCCATgcgATGATTGTCGATGAAG & \\
\hline
\end{tabular}

pMD18-T. Simple vector E. coli DH5 $\alpha$ was transformed with these plasmids using the heat shock method. Bluewhite selection was conducted on flat LB plates containing ampicillin $(100 \mathrm{mg} / \mathrm{mL})$ to select recombinant colonies for expansion in liquid culture. Recovered plasmids with the correct restriction pattern were sent to Sangon Biotech for gene sequencing. The sequence analysis confirmed that cDNAs from pMD18-T were subcloned to pET-28b and introduced into E.coli BL21 (DE3) for protein expression.

\section{Determination of a mutation point of the $\beta$-CGTase gene}

The three bacterial strains expressing the $\beta$-CGTase mutants were named Y127F, R254F and D355R. Recombinant proteins were purified and subjected to western blotting using mouse anti-6-His monoclonal antibody. The medium containing the $\beta$-CGTase expressing strains was collected after shake cultivation for $8 \mathrm{~h}$, and then $1 \%$ lactose was added overnight for induction of protein expression. After shake cultivation for an additional $8 \mathrm{~h}$, a solution containing $0.5 \%$ Triton X-100 and $1 \%$ glycine was added, before centrifugation at $6000 \times g, 4{ }^{\circ} \mathrm{C}$ for $10 \mathrm{~min}$. The supernatant was dialyzed against $4 \mathrm{~L}$ of a $20 \mathrm{mM}$ phosphate buffer, $\mathrm{pH} 7.0$ at $4{ }^{\circ} \mathrm{C}$ for $24 \mathrm{~h}$ and then loaded onto a His-Tag affinity column (General Electrics) for purification. The expression was confirmed by SDS-PAGE and western blotting.

\section{Enzyme activity assays}

The enzyme activity assays were conducted with soluble corn starch as a substrate and measured spectroscopically. The reaction medium $(0.01 \mathrm{~mL}$ of the enzyme solution, $0.2 \mathrm{~mL}$ of $0.2 \%$ starch solution, $0.2 \mathrm{~mL}$ of a $0.2 \mathrm{M}$ glycine$\mathrm{NaOH}$ buffer $\mathrm{pH} 9.0$ ) was incubated in a water bath at $40{ }^{\circ} \mathrm{C}$ for $10 \mathrm{~min}$ (Rimphanitchayakit et al. 2005). $100 \mu \mathrm{L}$ of $4 \mathrm{mM}$ iodine in $30 \mathrm{mM}$ potassium iodide was added to the reaction and diluted to $10 \mathrm{~mL}$ with water. The starch iodine complex formation was quantified by measuring absorbance at $700 \mathrm{~nm}$. One unit of enzyme activity was defined as the amount that elicited a $10 \%$ reduction in absorbance (Gawande et al. 2003). In the formula below, ' $a$ ' is the optical density $(\mathrm{OD} / \mathrm{min})$ of the reaction from the control group, and ' $\mathrm{b}$ ' is the OD of the reaction from the sample.

$U / \mathrm{mL}=\frac{a-b}{a} \times 1000 \times$ dilution factor

\section{Activity-pH profile}

The optimum $\mathrm{pH}$ of the purified enzymes was determined by replacing $0.2 \mathrm{M}$ glycine- $\mathrm{NaOH}$ buffer $(\mathrm{pH} 9.0)$ with either $0.2 \mathrm{M}$ sodium acetate buffer ( $\mathrm{pH} 4-5), 0.2 \mathrm{M}$ sodium phosphate buffer ( $\mathrm{pH}$ 6-7), or glycine- $\mathrm{NaOH}$ buffer ( $\mathrm{pH} 8-10)$. Reactions were performed following the previous procedures described for the enzyme activity assay.

\section{Activity-temperature profile}

The optimum temperature of the purified enzymes was determined by incubating the reaction mixture at different temperatures, ranging from 30 to $80{ }^{\circ} \mathrm{C}$ for $10 \mathrm{~min}$. Reactions were performed following the previous procedures described for the enzyme activity assay.

\section{pH stability profile}

The $\mathrm{pH}$ stability of the enzymes was measured by incubating $0.1 \mathrm{~mL}$ pure enzyme with $0.2 \mathrm{~mL}$ of $0.2 \mathrm{M}$ sodium acetate buffer ( $\mathrm{pH} 4-5), 0.2 \mathrm{M}$ sodium phosphate buffer (pH 6-7) or glycine- $\mathrm{NaOH}$ buffer $(\mathrm{pH} 8-10)$, at $60{ }^{\circ} \mathrm{C}$, and without substrate for $60 \mathrm{~min}$. The CGTase assay procedure described above was followed to determine the residual activity of the enzyme.

\section{Thermal stability profile}

The thermal stability of the enzymes was measured by incubating $0.1 \mathrm{~mL}$ pure enzyme with $0.2 \mathrm{~mL}$ buffer $(0.2 \mathrm{M}$ sodium phosphate buffer, $\mathrm{pH}$ 6.0) without substrate at different temperatures $\left(30-80{ }^{\circ} \mathrm{C}\right)$ for $60 \mathrm{~min}$. The 
standard CGTase activity assays described above was used to determine the residual activity of each enzyme (Jeang et al. 2005).

\section{Kinetic assays}

The $K_{\mathrm{m}}$ and $V_{\max }$ values for the purified enzymes were determined by incubating $100 \mu \mathrm{L}$ of enzyme $(0.5 \mu \mathrm{g})$ in $200 \mu \mathrm{L}$ of $0.2 \mathrm{M}$ phosphate buffer ( $\mathrm{pH}$ 6.0) with soluble starch solution $(0.4-6.0 \mathrm{mg} / \mathrm{mL})$ at $60{ }^{\circ} \mathrm{C}$ for $10 \mathrm{~min}$. The kinetic parameters of $K_{\mathrm{m}}$ and $V_{\max }$ were obtained by a nonlinear least-square fitting procedure using the Michaelis-Menten equation and the curve fitting software (Origin 8.0).

\section{Results}

\section{Generation of the $\beta$-CGTase mutants}

The overlap extension PCR was used for site-directed mutagenesis of the generation of the $\beta$-CGTase mutants, and three mutagenic primers were designed at three key positions of $\beta$-CGTase. As shown in Fig. 1a, the first-round PCR using primers $\mathrm{F} 1$ and $\mathrm{R} 1$ yielded a pattern containing 6 different bands following agarose gel electrophoresis. Lanes 1 and 2 were the two fragments of mutant gene of $\mathrm{R} 254 \mathrm{~F}$, the fragments length was, respectively, 762 and $1377 \mathrm{bp}$; lanes 3 and 4 were the two fragments of mutant gene of D355R, the fragments length was, respectively, 1065 and 1074 bp; lanes 5 and 6 were the two fragments of mutant gene of Y127F, the fragments length was, respectively, 381 and 1758 bp. The second round extension PCR

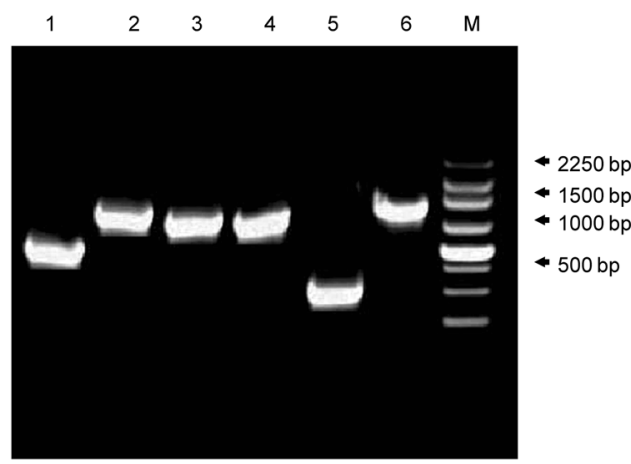

a

Fig. 1 Verification of the mutant constructs generation. a Band pattern observed after first round PCRs using primers F1 and R1. Lane $M$ molecular weight marker (1-250 bp); lanes 1 and 2 ORF-1 and ORF-2 of F substituted for R254; lanes 3 and 4 ORF-1 and ORF2 of $\mathrm{R}$ substituted for D355; lanes 5 and 6 ORF-1 and ORF-2 of F using primers F2 and R2 yielded complete mutant genes. Agarose electrophoresis analysis of the mutation genes showed that there were three specific bands of $2.1 \mathrm{kbp}$ (from lanes 2 to 4 ), respectively. The size of the mutant genes was similar with genes of $\beta$-CGTase (lane 1) (Fig. 1b).

We prepared the amino sequence alignment of $\beta$ CGTase from Bacillus sp. (142676), Bacillus circulans (39420) and Paenibacillus sp. Xw-6-66 (452182092). The location of each mutant within the primary amino acid sequence of the $\beta$-CGTase is shown in Fig. 2, where the 5 domains of $\beta$-CGTase and the mutation sites were highlighted.

We examined the gene products of the cloned $\beta$ CGTases fragment and its mutants by in vitro protein synthesis using an $E$. coli extract system. The recombinant expression plasmids were transformed into E. coli BL21 (DE3). Following induction of protein expression overnight using $1 \%$ lactose, we lysed the bacteria and obtained the mutant proteins, performed SDS-PAGE analysis of the proteins and the purifications (Fig. $3 \mathrm{a}-\mathrm{c}$ ). A band of about $70 \mathrm{kDa}$ for the wild type $\beta$-CGTase (lane 1, Fig. 3a, b) and all mutant constructs (lanes 2-4, Fig. 3a, b) were observed. The novel combination of the modern molecular approaches used in this study for generation of $\beta$-CGTase mutants seems to be suitable for quick, reliable and simple. Mutant $\beta$-CGTase was constructed into the $\mathrm{pET}-28 \mathrm{a}$ vector that harbors His-tag. To detect the expression of mutant $\beta$ CGTase, Western blot analysis was performed with antiHis antibody. Western blotting for expression of the fusion His-tagged recombinant protein was shown in Fig. 3c. A band at about $70 \mathrm{kDa}$ was observed for the wild type $\beta$ CGTase (lane 3) and the mutants (lanes 4-6), while the lane 1 and lane 2 were obtained with E. coli strain BL21 (DE3) and pET-28b.

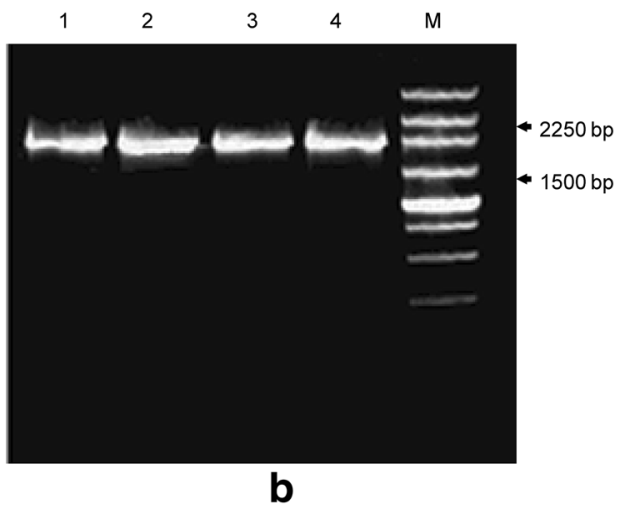

substituted for Y127. b Band pattern observed after second-round PCRs using primers F2 and R2. Lane $M$ molecular weight marker (1-250 bp); lane 1 the wild type $\beta$-CGTase; lane $2 \mathrm{~F}$ substituted for Y127; lane $3 \mathrm{R}$ substituted for R254; lane $4 \mathrm{~F}$ substituted for D355 


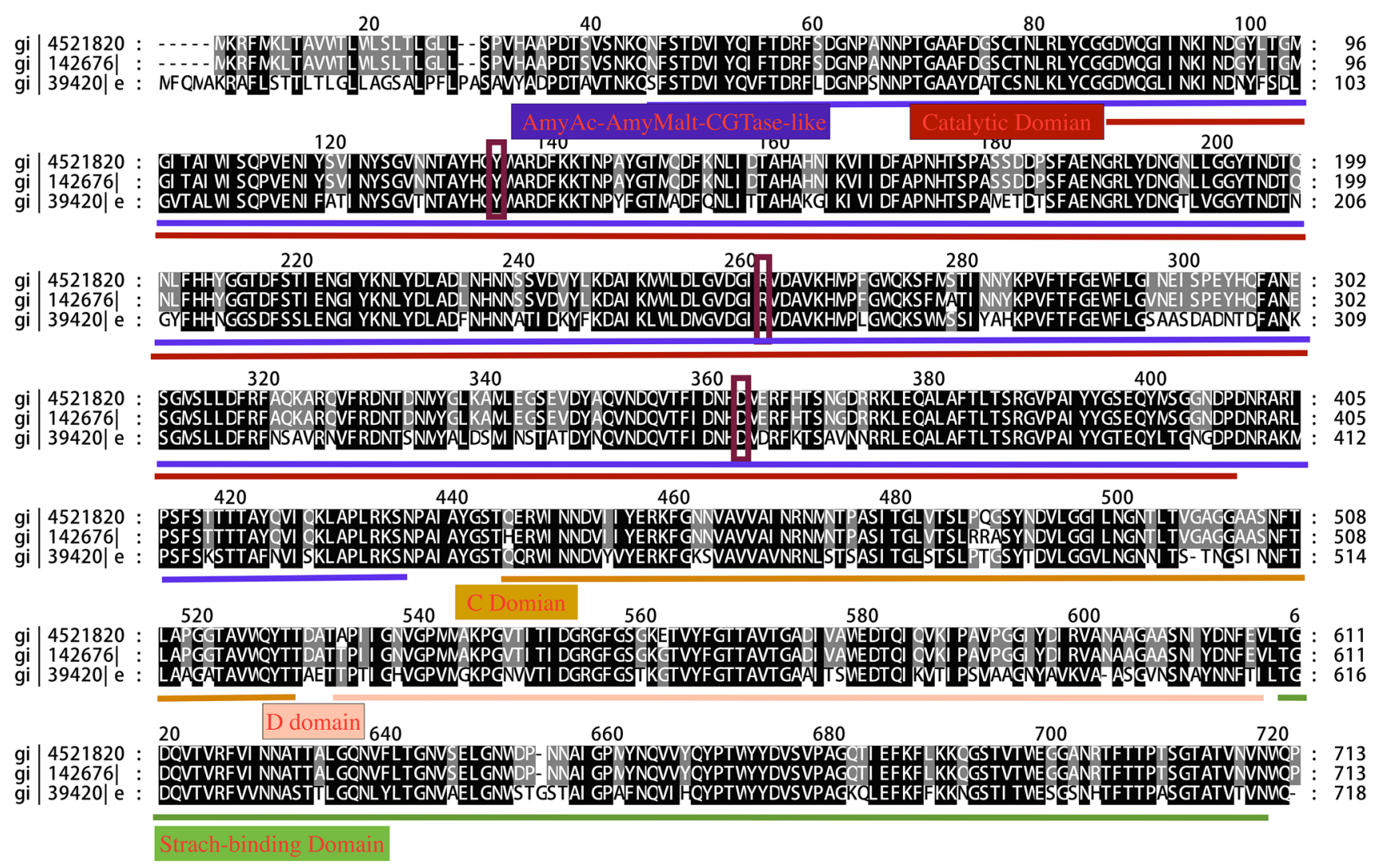

Fig. 2 Amino acid sequence alignment of the $\beta$-CGTases. The conserved domains of $\beta$-CGTases are shown with different colors. The mutation sites Y127, R254 and D355 are highlighted with red box

\section{Enzyme activity assays}

We tested relative enzyme activity of the wild type $\beta$ CGTase and Y127F, R254F, and D355R mutant $\beta$-CGTases and the results are listed in Tables 2 and 3. The data showed that cyclization activity of the mutant $\beta$-CGTases was increased to $2130-1660 \mathrm{U} / \mathrm{mL}$ compared to $1012 \mathrm{U} / \mathrm{mL}$ for the wild type $\beta$-CGTase, indicating a 1.6 to 2.1 -fold activity enhancement.

The kinetic parameters for the $\beta$-CGTase and its mutants $\mathrm{Y} 127 \mathrm{~F}, \mathrm{R} 254 \mathrm{~F}$, and D355R were measured using the starch substrate and they are tabulated in Table 3. The $V_{\max }$ values in the range of 22.02 and $21.41 \mu \mathrm{g} / \mathrm{min}$ for the mutant proteins were higher than $21.00 \mu \mathrm{g} / \mathrm{min}$ for the parent wild type $\beta$-CGTase. Meanwhile, the observed $k_{\text {cat }}$ values varying between 73.40 and $71.37 / \mathrm{s}$ for the mutant $\beta$ CGTases were also higher than the number of $70.00 / \mathrm{s}$ for the wild type $\beta$-CGTase. The ratio of $k_{\mathrm{cat}} / K_{\mathrm{m}}$ for $\mathrm{Y} 127 \mathrm{~F}$, $\mathrm{R} 254 \mathrm{~F}$, and $\mathrm{D} 355 \mathrm{R}$ variants was $4.80,4.04$, and $4.10 / \mathrm{s} /$ $\mathrm{mM}$, respectively, compared to $3.65 / \mathrm{s} / \mathrm{mM}$ for the wild type $\beta$-CGTase. The ratio suggested how efficiently a catalytic enzyme converts a substrate into products. A higher ratio indicates a higher efficiency of the enzyme.
The increased ratio of $1.15,0.39$, and 0.45 for the mutants compared to the wild type $\beta$-CGTase indicates enhanced catalytic activity for the mutants which was consistent with the enzyme activity assay.

The Michaelis constant $K_{\mathrm{m}}$ is an indicator of the substrate's affinity for the enzyme. As shown in Table 3, the observed $K_{\mathrm{m}}$ was lowered by $3.90,1.40$, and $1.80 \mathrm{mM}$ for the Y127F, R254F, and D355R mutants to $15.30,17.80$, and $17.40 \mathrm{mM}$ from $19.20 \mathrm{mM}$ for the wild type $\beta$ CGTase. This observation indicates that all the three mutants had higher affinity towards the starch substrate than the parent $\beta$-CGTase.

\section{Determination of pH optima using a starch substrate}

The activity of the wild type and mutant forms of the $\beta$ CGTase as a function of $\mathrm{pH}$ was examined over a $\mathrm{pH}$ range of 4-8 in a universal buffer using the starch substrate (Fig. 4a). The activity-pH profiles for the Y127F, R254F, and D355R mutants were similar to that for the wild type $\beta$-CGTase. The highest activity was observed at $\mathrm{pH} 6.0$ for all the four enzymes, indicating limited influence of the single site mutation on the activity-pH relationship. 
Fig. 3 SDS-PAGE and western blotting validation of the mutant enzyme expression and purification. a SDS-PAGE validation of mutant enzyme expression; b SDS-PAGE validation of mutant enzyme purification; Lane $M$ molecular weight marker of protein; lane 1 the wild type $\beta$-CGTase; lane 2 Y127F; lanes 3 R254F; lane 4 D355R. c Western blotting for expression of the wild type and mutant proteins; Lane $M$ molecular weight marker of protein; lane 1 Escherichia coli strain BL21 (DE3); lane 2 pET$28 \mathrm{~b}$; lane 3 the wild type $\beta$ CGTase; lane 4 Y127F mutant; lane $5 \mathrm{R} 254 \mathrm{~F}$ mutant; lane 6 D355R mutant

Table 2 Enzymatic activity of wild type $\beta$-CGTase and the Y127F, R254F, and D355R mutants
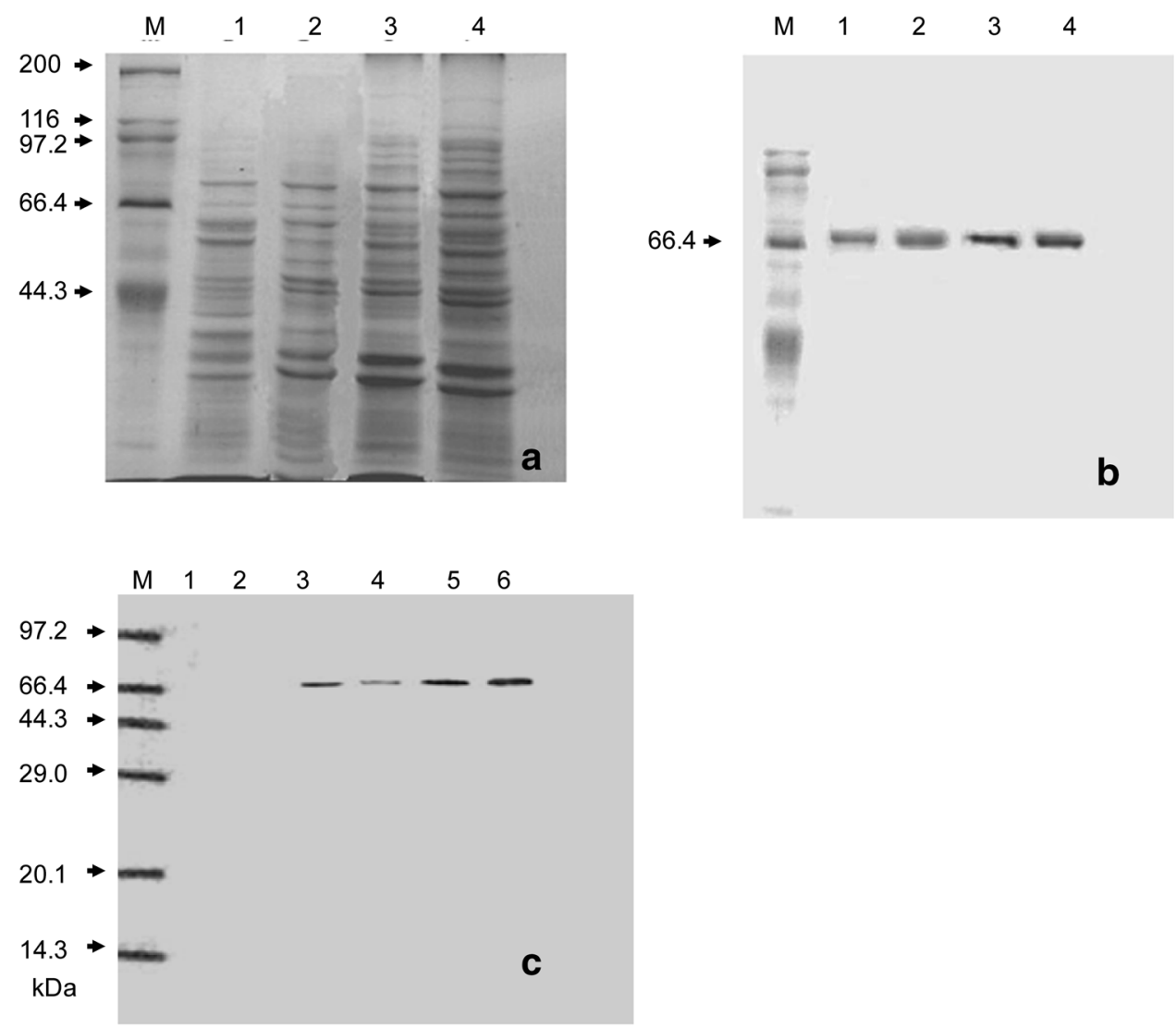

\begin{tabular}{lll}
\hline & Total activity $(\mathrm{U} / \mathrm{mL})$ & Relative value $^{\mathrm{a}}$ \\
\hline$\beta$-CGTase & $1012.33 \pm 1.528$ & 1.00 \\
Y127F & $2130.27 \pm 1.598^{*}$ & 2.10 \\
R254F & $1985.46 \pm 2.006^{*}$ & 1.96 \\
D355R & $1660.75 \pm 1.720^{*}$ & 1.64 \\
\hline
\end{tabular}

* The mean difference is significant at the $P<0.01$ level

a The ratio of total activity to mutants and $\beta$-CGTase. Experiments were performed in triplicate

Table 3 Kinetic parameters of $\beta$-CGTase and mutants

\begin{tabular}{lllll}
\hline Bacterial strain & $K_{m}(\mathrm{mM})$ & $V_{\max }(\mu \mathrm{g} / \mathrm{min})$ & $k_{\text {cat }}(\mathrm{per} \mathrm{s})$ & $k_{\text {cat }} / K_{\mathrm{m}}(\mathrm{per} \mathrm{s} / \mathrm{mM})$ \\
\hline$\beta$-CGTase & $19.20 \pm 1.747$ & $21.00 \pm 1.185$ & $70.00 \pm 3.950$ & 3.65 \\
Y127F & $15.30 \pm 1.236$ & $22.02 \pm 1.146$ & $73.40 \pm 3.820$ & 4.80 \\
R254F & $17.80 \pm 1.327$ & $21.60 \pm 1.284$ & $72.00 \pm 4.280$ & 4.04 \\
D355R & $17.40 \pm 1.556$ & $21.41 \pm 0.974$ & $71.37 \pm 3.247$ & 4.10 \\
\hline
\end{tabular}

\section{pH stability using a starch substrate}

The activity of each enzyme without pre-incubation in the buffer at $\mathrm{pH} 6.0$ was defined as $100 \%$. All the enzymes, including the wild type, were relatively stable at $\mathrm{pH} 4-7$ with residual activity of more than $90 \%$. However, they all became unstable at higher $\mathrm{pH}$ as indicated by the residual activity dropping from $85 \%$ at $\mathrm{pH} 8.0$ to less than $30 \%$ at $\mathrm{pH} 10$. The stability as a function of $\mathrm{pH}$ for the wild type and mutant forms of the $\beta$-CGTase was tested between $\mathrm{pH} 4$ and $\mathrm{pH} 10$ in a universal buffer (Fig. 4b). It is important to note that all mutants yielded stability 


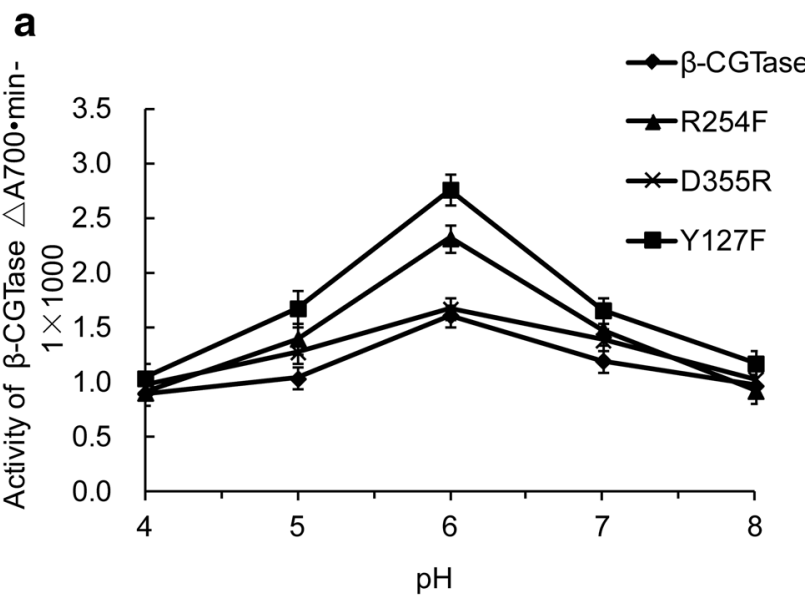

b

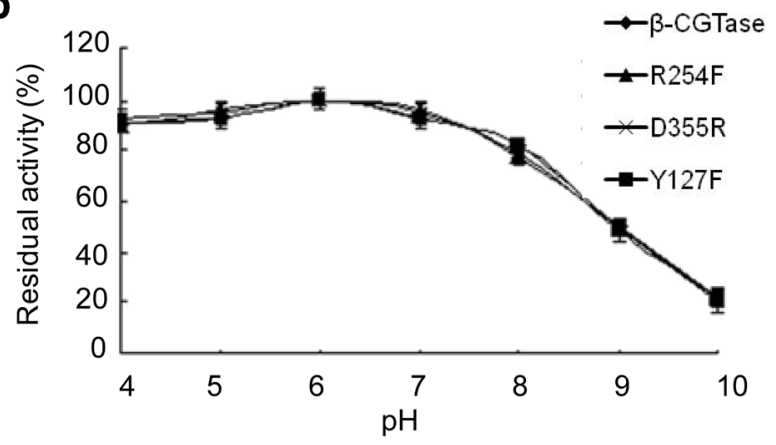

Fig. 4 Activity-pH profiles and stability of the wild type and mutant $\beta$-CGTases. a Activity-pH profiles of the wild type and mutant $\beta$ CGTases; $\mathbf{b}$ stability-pH of the wild type and mutant $\beta$-CGTases. The activity of the wild type $\beta$-CGTase and its mutants was measured using $0.01 \mathrm{~mL}$ of the enzyme solution mixed with $0.2 \mathrm{~mL}$ of $0.2 \%$ starch solution in a $0.2 \mathrm{M}$ universal buffer at $37{ }^{\circ} \mathrm{C}$ for $2 \mathrm{~h}$

curves which were very similar to that of the wild type enzyme $(P>0.05)$.

\section{Activity-temperature profile}

The optimal temperatures and thermostability of mutants and were compared to $\beta$-CGTase (Fig. 5a, b). The effect of temperature on the $\beta$-CGTase activity was investigated using the starch substrate at temperatures between 30 and $80{ }^{\circ} \mathrm{C}$ for $10 \mathrm{~min}$ at the optimal pH 6.0 for each enzyme (Fig. 5a). The optimal temperature for all the enzymes including the wild type $\beta$-CGTase was $60{ }^{\circ} \mathrm{C}$. The activity-temperature profiles for the wild type $\beta$-CGTase and the mutants were very similar.

They were both optimally active at $30-60{ }^{\circ} \mathrm{C}$, at temperatures from 30 to $60{ }^{\circ} \mathrm{C}$, all the four $\beta$-CGTases retained at least $90 \%$ of the original activity for at least $1 \mathrm{~h}$ (Fig. 5b). Enzymatic activity gradually decreased when temperature exceeded $60{ }^{\circ} \mathrm{C}$ for all the enzymes. The observed residual activity at $70{ }^{\circ} \mathrm{C}$ was about $40 \%$, and the activity decreased to $25 \%$ at $80{ }^{\circ} \mathrm{C}$. Thus, the mutation did not have significant negative effect on stability when compared to the wild type $\beta$-CGTase $(P>0.05)$; the
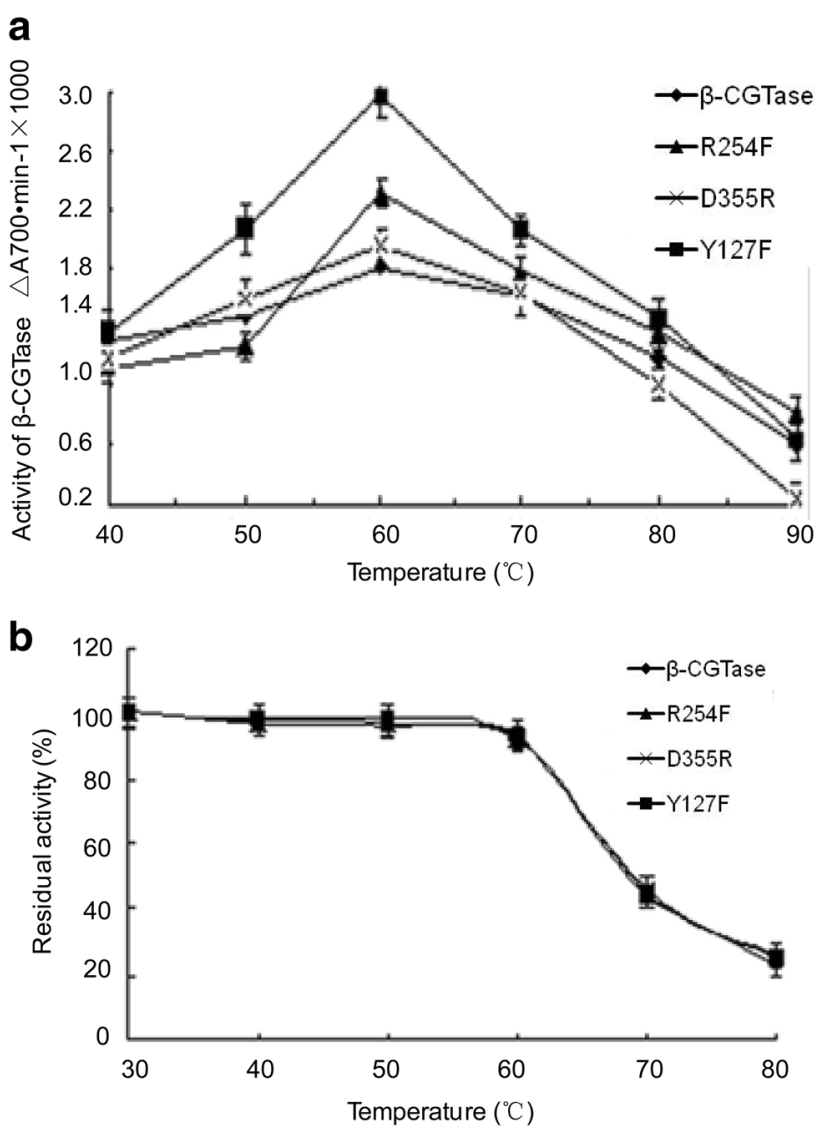

Fig. 5 Activity-temperature profiles and thermal stability for the wild type and mutant $\beta$-CGTases. a Activity-temperature profiles of the wild type $\beta$-CGTase and its mutants; $\mathbf{b}$ thermal stability of the wild type $\beta$-CGTase and its mutants

cyclization assays were performed as described (Penninga et al. 1995).

\section{Discussion}

$\beta$-CGTase is one of the important $\alpha$-amylase family, and CGTase is the first enzyme of all the transglycosylases. In general, the cyclization activity of CGTases is much higher than the disproportionation and hydrolysis activities.

In this work, we engineered the mutants of $\beta$-CGTase by site-directed mutagenesis with the attempt to improve catalytic cyclization activity of $\beta$-CGTase. The three mutants (Y127F, R254F, and D355R) showed enhanced activity of $\beta$-CGTase. Interestingly, these mutant residues were all involved in the activity center of the enzyme, and they were located at the bottom of the 'pocket' in the $\mathrm{N}$-terminal of the $\beta$-CGTase. The $\mathrm{NH}_{2}$-terminal region of CGTase was important for cyclization characteristics, so the mutations would improve the activity of $\beta$-CGTase (Penninga et al. 1995). Fujiwara et al. (1992a, b) constructed the CGTase gene from Bacilus stearothermophilus 
Fig. 6 Schematic representation of the reactions catalyzed by CGTase. After bond cleavage a covalently bound reaction enzyme glucosyl intermediate is formed. In the second step of the reaction the reaction intermediate is transferred to an acceptor molecule. In the cyclization reaction, the terminal $\mathrm{OH}^{-4}$ group of the covalently linked oligosaccharide is used as acceptor, whereas water or a second sugar is used as acceptors in the hydrolysis and disproportionation reactions, respectively. This figure has been adapted from Ref. Leemhuis et al. (2004a)
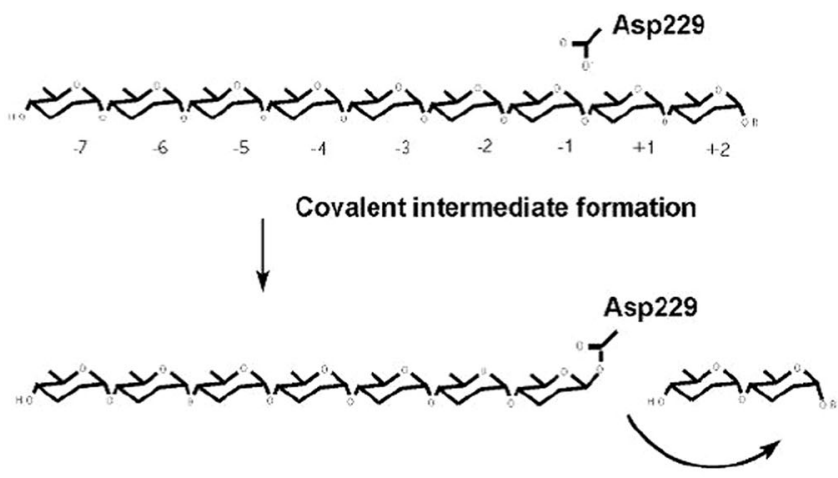

Acceptor binding
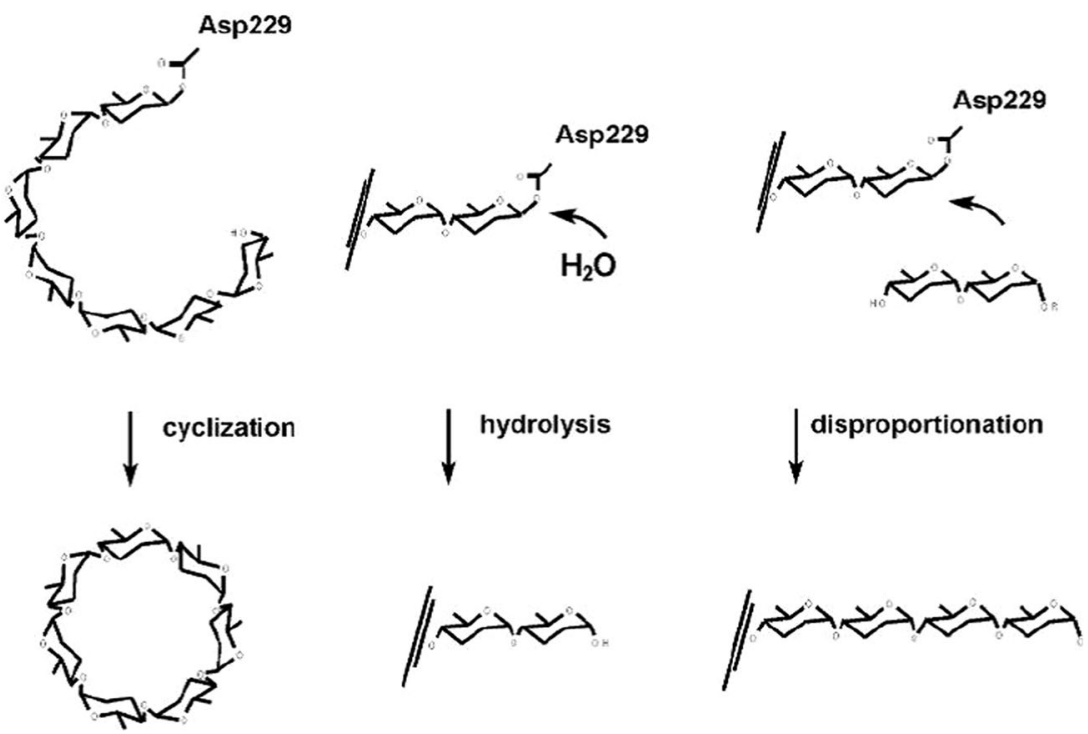

No2. Cgtl-F191Y (Phe at position 191 was replaced by Tyr) was constructed for the analysis of the $\mathrm{NH}_{2}$-terminal region. The industrial production of cyclodextrins might be improved by the construction of mutant CGTase with improved activity of $\beta$-CGTase.

Each of these mutations was predicted to alter the hydrophobicity of a conserved domain within the $\beta$ CGTase by Support Vector Machine. Since single site mutations of the $\beta$-CGTase occurred at three different sites (127, 254, and 355) and their relative positions in the substrate-binding cleft (pocket) were expected to have different influence on the incoming starch substrate, it is difficult to discuss the activity-structure relationship. However, analysis of the observed cyclization activity of each of the three mutants and their wild type $\beta$-CGTase displayed a trend that increasing hydrophobicity of the catalytic center domain appeared to favor the cyclization activity of the mutants. The D355R mutant $\beta$-CGTase replacing a hydrophilic aspartic acid (D, hydropathy index $=\mathrm{HI}=-3.5)$ with a hydrophilic arginine (R, $\mathrm{HI}=-4.5)$ enhanced the enzyme activity to 1.6 -folds. More significant enzyme activity enhancements (1.9 and 2.1-fold) were observed for the Y127F and R254F mutant $\beta$-CGTases where a hydrophilic tyrosine (Y, $\mathrm{HI}=-1.3$ ) or arginine $(\mathrm{R})$ was replaced with a hydrophobic phenylalanine $(\mathrm{F}, \mathrm{HI}=2.8)$, respectively.

It was assumed that the cyclization was taken by nucleophilic attack, and the key amino acid residues in the cyclization reaction were aspartic acid 229 in the cyclization reaction (Wind et al. 1998). When aspartic acid 229 nucleophilic attack $\mathrm{C} 1$ as shown in Fig. 6, the carboxyl ionization, the arginine with positive charge took the place of the negatively charged aspartic acid 355 , the existence of positive charge was more advantageous to ASP229 nucleophilic attack $\mathrm{C} 1$, and conducive to Asp229 nucleophilic attack $\mathrm{C} 1$, and conducive to the substrate cyclization (Chung et al. 1998; Kragh et al. 2010).

In mutant of R254F, phenylalanine with a pair of conjugate lone pair electrons was advantageous to the 
hydrophobic stacking effect and conducive to the stability of the seventh sugar molecules cyclization. For the mutant $\beta$-CGTase-Y127F, the hydrophobic phenylalanine blocked the entering $\mathrm{H}_{2} \mathrm{O}$ into the active center, which restrained the hydrolysis and enhanced the cyclization. This result is similar with previous report (Leemhuis et al. 2003c).

The mutant proteins were successfully expressed and purified. The molecular weight of the purified mutant proteins was about $70 \mathrm{kDa}$, which was consistent with the expected values as reported by Nomoto et al. (1986). These enzymes present common properties with the majority of the reported CGTases which are monomeric with a molecular mass ranging from 60 to $110 \mathrm{kDa}$ (Biwer et al. 2002; Nomoto et al. 1986).

The optimum $\mathrm{pH}$ of the mutants was $\mathrm{pH}$ 6.0, which was in accord with some other CGTases from alkalophilic Bacillus sp. G1 (Cao et al. 2005) and B. stearothermophilus ET1 (Sian et al. 2005). However, the mutants showed lower activity at $\mathrm{pH} 4.0$ and 8.0 , suggested that the mutants and wild type of $\beta$-CGTase required a near-neutral $\mathrm{pH}$ range to perform its reaction. Extreme $\mathrm{pH}$ values were not suitable for the enzyme to carry out cyclization activity. Most of the reported CGTases exhibited optimum $\mathrm{pH}$ range from 5.0 to 8.0 (Bovetto et al. 1992; Chung et al. 1998; Tachibana et al. 1999; Sian et al. 2005), but the enzyme from Brevi-bacterium sp. no. 9605 possessed a higher optimum pH value at 10.0 (Cao et al. 2005).

The $\mathrm{pH}$ stability for cyclization is broad, in the range of $\mathrm{pH}$ 4.5-9.0, indicating that the mutants have not changed the $\mathrm{pH}$-dependent activity of $\beta$-CGTase. A similar observation implying that the mutants of $\beta$-CGTase were related to $\mathrm{pH}$ stability has been also reported by Kimura et al. who constructed mutants by deleting the C-terminus of the CGTase from the alkalophilic Bacillus sp. \#1011 (Mori et al. 1994).

The optimal temperature for all the enzymes including the wild type $\beta$-CGTase was $60{ }^{\circ} \mathrm{C}$, and they were both optimally active at $30-60{ }^{\circ} \mathrm{C}$. The activity-temperature profiles for the wild type $\beta$-CGTase and the mutants were very similar. Studies by other researchers on CGTase from B. autolyticus 11149, B. stearothermophilus (Tomita et al. 1993) and B. circulans E 192 (Chung et al. 1998) also found $60{ }^{\circ} \mathrm{C}$ was the optimum temperature, which is in agreement with mutants. And the enzymes had not a higher temperature stability compared to CGTase from alkalophilic Bacillus sp. G1 (Cao et al. 2005).

In vitro site-directed mutagenesis was performed to introduce Y127, R254 and D355 mutations in a conserved region of the $\beta$-CGTase enzyme. The mutant proteins were successfully expressed and purified. The Y127F, R254F, and D355R mutant $\beta$-CGTases exhibited a similar optimal temperature, optimal $\mathrm{pH}$, thermal stability, and $\mathrm{pH}$ stability as the wild type $\beta$-CGTase. However, all the three mutants displayed a higher activity towards the corn starch substrate than the wild type $\beta$-CGTase. Increasing hydrophobicity around the substrate-binding cleft of the catalytic center appeared to enhance the cyclization activity of the enzymes.

Acknowledgements This research was supported by Inner Mongolia Natural Science Foundation (2015BS0312, China).

\section{Compliance with ethical standards}

Conflict of interest All the authors declare that they have no conflicts of interest regarding this paper.

\section{References}

Angelaccio S, di Patti MCB (2002) Site-directed mutagenesis by the megaprimer PCR method: variations on a theme for simultaneous introduction of multiple mutations. Anal Biochem 306:346-349

Astray G, Mejuto JC, Morales J, Rial-Otero R, Simal-Gandara J (2010) Factors controlling flavors binding constants to cyclodextrins and their applications in foods. Food Res Int 43:1212-1218

Bautista V, Esclapez J, Perez-Pomares F, Martinez-Espinosa RM, Camacho M, Bonete MJ (2012) Cyclodextrin glycosyltransferase: a key enzyme in the assimilation of starch by the halophilic archaeon Haloferax mediterranei. Extremophiles 16:147-159

Biwer A, Antranikian G, Heinzle E (2002) Enzymatic production of cyclodextrins. Appl Microbiol Biot 59:609-617

Bovetto LJ, Villette JR, Fontaine IF, Sicard PJ, Bouquelet SJL (1992) Cyclomaltodextrin Glucanotransferase from Bacillus-Circulans E-192.2. Action Patterns Biotechnol Appl Bioc 15:59-68

Cao XZ, Jin ZY, Wang X, Chen F (2005) A novel cyclodextrin glycosyltransferase from an alkalophilic Bacillus species: purification and characterization. Food Res Int 38:309-314

Chung HJ et al (1998) Characterization of a thermostable cyclodextrin glucanotransferase isolated from Bacillus stearothermophilus ET1. J Agric Food Chem 46:952-959

Fujiwara S, Kakihara H, Sakaguchi K, Imanaka T (1992a) Analysis of mutations in cyclodextrin glucanotransferase from Bacillusstearothermophilus which affect cyclization characteristics and thermostability. J Bacteriol 174:7478-7481

Fujiwara S, Kakihara H, Woo KB, Lejeune A, Kanemoto M, Sakaguchi K, Imanaka T (1992b) Cyclization characteristics of cyclodextrin glucanotransferase are conferred by the nh2-terminal region of the enzyme. Appl Environ Microb 58:4016-4025

Gawande BN, Sonawane AM, Jogdand VV, Patkar AY (2003) Optimization of cyclodextrin glycosyltransferase production from Klebsiella pneumoniae AS-22 in batch, fed-batch, and continuous cultures. Biotechnol Prog 19(6):1697-1702

Goh KM, Mahadi NM, Hassan O, Rahman RNZRA, Illias RM (2009) A predominant beta-CGTase G1 engineered to elucidate the relationship between protein structure and product specificity. J Mol Catal B-Enzym 57:270-277

Hyun-Dong S, Park TH, Lee YH (2000) Site-directed mutagenesis and functional analysis of maltose-binding site of beta-cyclodextrin glucanotransferase from Bacillus firmus var. alkalophilus. Biotechnol Lett 22:115-121

Janecek S (2002) How many conserved sequence regions are there in the alpha-amylase family? Biologia 57:29-41

Janecek S, Sevcik J (1999) The evolution of starch-binding domain. FEBS Lett 456:119-125

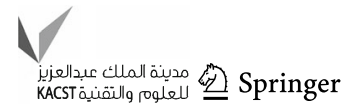


Jeang CL, Lin DG, Hsieh SH (2005) Characterization of cyclodextrin glycosyltransferase of the same gene expressed from Bacillus macerans, Bacillus subtilis, and Escherichia coli. J Agr Food Chem 53:6301-6304

Klein C, Hollender J, Bender H, Schulz GE (1992) Catalytic Center of cyclodextrin glycosyltransferase derived from X-ray structureanalysis combined with site-directed mutagenesis. Biochemistry 31:8740-8746

Kragh KM, Leemhuis H, Dijkhuizen L, Dijkstra BW (2010) Cyclodextrin glycosyltransferase (CGTase) polypeptides with modified hydrolysis activity. United States Patent. Lubbert Dijkhuizen, Zuidlaren, Cambridge

Lawson CL, Van montfort R, Strokopytov B, Rozeboom HJ, Kalk KH, De vries GE, Penninga D, Dijkhuizen L, Dijkstra BW (1994) Nucleotide-sequence and X-ray structure of cyclodextrin glycosyltransferase from Bacillus-circulans strain-251 in a maltose-dependent crystal form. J Mol Biol 236:590-600

Leemhuis H, Dijkstra BW, Dijkhuizen L (2002a) Mutations converting cyclodextrin glycosyltransferase from a transglycosylase into a starch hydrolase. FEBS Lett 514:189-192

Leemhuis H, Uitdehaag JCM, Rozeboom HJ, Dijkstra BW, Dijkhuizen L (2002b) The remote substrate binding subsite-6 in cyclodextrin-glycosyltransferase controls the transferase activity of the enzyme via an induced-fit mechanism. J Biol Chem 277:1113-1119

Leemhuis H, Kragh KM, Dijkstra BW, Dijkhuizen L (2003a) Engineering cyclodextrin glycosyltransferase into a starch hydrolase with a high exo-specificity. J Biotechnol 103:203-212

Leemhuis H, Rozeboom HJ, Dijkstra BW, Dijkhuizen L (2003b) The fully conserved Asp residue in conserved sequence region I of the alpha-amylase family is crucial for the catalytic site architecture and activity. FEBS Lett 541:47-51

Leemhuis H, Rozeboom HJ, Wilbrink M, Euverink GJW, Dijkstra BW, Dijkhuizen L (2003c) Conversion of cyclodextrin glycosyltransferase into a starch hydrolase by directed evolution: the role of alanine 230 in acceptor subsite +1 . Biochemistry 42:7518-7526

Leemhuis H, Rozeboom HJ, Dijkstra BW, Dijkhuizen L (2004a) Improved thermostability of Bacillus circulans cyclodextrin glycosyltransferase by the introduction of a salt bridge. Proteins 54:128-134

Leemhuis H, Wehmeier UF, Dijkhuizen L (2004b) Single amino acid mutations interchange the reaction specificities of cyclodextrin glycosyltransferase and the acarbose-modifying enzyme acarviosyl transferase. Biochemistry 43:13204-13213

Leemhuis H, Kelly RM, Dijkhuizen L (2010) Engineering of cyclodextrin glucanotransferases and the impact for biotechnological applications. Appl Microbiol Biot 85:823-835

MacGregor EA, Janecek S, Svensson B (2001) Relationship of sequence and structure to specificity in the alpha-amylase family of enzymes. Biochim Biophys Acta 1546:1-20

Mori S, Hirose S, Oya T, Kitahata S (1994) Purification and properties of cyclodextrin glucanotransferase from Brevibacterium Sp No-9605. Biosci Biotech Bioch 58:1968-1972

Nomoto M, Chen CC, Sheu DC, (1986) Purification and characterization of cyclodextrin glucanotransferase from an alkalophilic bacterium of Taiwan. Agric Biol Chem 50(11):2701-2707
Penninga D, Strokopytov B, Rozeboom HJ, Lawson CL, Dijkstra BW, Bergsma J, Dijkhuizen L (1995) Site-directed mutations in tyrosine-195 of cyclodextrin glycosyltransferase from Bacilluscirculans strain-251 affect activity and product specificity. Biochemistry 34:3368-3376

Penninga D, van der Veen BA, Knegtel RM, van Hijum SA, Rozeboom HJ, Kalk KH, Dijkstra BW, Dijkhuizen L (1996) The raw starch binding domain of cyclodextrin glycosyltransferase from Bacillus circulans strain 251. J Biol Chem 271:32777-32784

Rimphanitchayakit V, Tonozuka T, Sakano Y (2005) Construction of chimeric cyclodextrin glucanotransferases from Bacillus circulans A11 and Paenibacillus macerans IAM1243 and analysis of their product specificity. Carbohydr Res 340(14):2279-2289

Sian HK, Said M, Hassan O, Kamaruddin K, Ismail AF, Rahman RA, Mahmood NAN, Illias RM (2005) Purification and characterization of cyclodextrin glucanotransferase from alkalophilic Bacillus sp G1. Process Biochem 40:1101-1111

Slominska L, Szostek A, Grzekowiak A (2002) Studies on enzymatic continuous production of cyclodextrins in an ultrafiltration membrane bioreactor. Carbohydr Polym 50:423-428

Stella VJ, He QR (2008) Cyclodextrins. Toxicol Pathol 36:30-42

Szejtli J (1990) The Cyclodextrins and their applications in biotechnology. Carbohydr Polym 12:375-392

Szente L, Szejtli J (2004) Cyclodextrins as food ingredients. Trends Food Sci Tech 15:137-142

Tachibana Y, Kuramura A, Shirasaka N, Suzuki Y, Yamamoto T, Fujiwara S, Takagi M, Imanaka T (1999) Purification and characterization of an extremely thermostable cyclomaltodextrin glucanotransferase from a newly isolated hyperthermophilic archaeon, a Thermococcus sp. Appl Environ Microb 65:1991-1997

Tomita K, Kaneda M, Kawamura K, Nakanishi K (1993) Purification and properties of a cyclodextrin glucanotransferase from Bacillus-autolyticus-11149 and selective formation of beta-cyclodextrin. J Ferment Bioeng 75:89-92

van der Veen BA, Uitdehaag JCM, Dijkstra BW, Dijkhuizen L (2000a) The role of arginine 47 in the cyclization and coupling reactions of cyclodextrin glycosyltransferase from Bacillus circulans strain 251-implications for product inhibition and product specificity. Eur J Biochem 267:3432-3441

van der Veen BA, Uitdehaag JCM, Penninga D, van Alebeek GJWM, Smith LM, Dijkstra BW, Dijkhuizen L (2000b) Rational design of cyclodextrin glycosyltransferase from Bacillus circulans strain 251 to increase alpha-cyclodextrin production. J Mol Biol 296:1027-1038

van der Veen BA, van Alebeek GJWM, Uitdehaag JCM, Dijkstra BW, Dijkhuizen L (2000c) The three transglycosylation reactions catalyzed by cyclodextrin glycosyltransferase from Bacillus circulans (strain 251) proceed via different kinetic mechanisms. Eur J Biochem 267:658-665

Wind RD, Uitdehaag JCM, Buitelaar RM, Dijkstra BW, Dijkhuizen L (1998) Engineering of cyclodextrin product specificity and $\mathrm{pH}$ optima of the thermostable cyclodextrin glycosyltransferase from Thermoanaerobacterium thermosulfurigenes EM1. J Biol Chem 273:5771-5779 